\title{
Community-wide consequences of variation in photoprotective physiology among prairie plants
}

\author{
S. KOTHARI',+, J. CAVENDER-BARES ${ }^{*, * *,+}$, K. BITAN ${ }^{* *}$, A.S. VERHOEVEN ${ }^{* * *}$, R. WANG $^{\#}$,

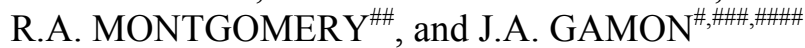

Plant Biological Sciences Program, University of Minnesota, 250 Biological Sciences Center, 1445 Gortner Avenue, Saint Paul, MN 55108, USA*

Department of Ecology, Evolution and Behavior, University of Minnesota, 100 Ecology,

1987 Upper Buford Circle, Saint Paul, MN 55108, USA ${ }^{* *}$

Department of Biology, University of St. Thomas, 2115 Summit Avenue, Saint Paul, MN 55105, USA $A^{* * *}$

Department of Earth and Atmospheric Sciences, University of Alberta, Edmonton, AB, T6G 2E9, Canada \#

Department of Forest Resources, University of Minnesota, 115 Green Hall, 1530 Cleveland Ave. N., St. Paul, MN 55108, USA \#\#

Center for Advanced Land Management Information Technologies, School of Natural Resources, University of Nebraska-Lincoln, Lincoln, NE 68583, USA \#\#\#

Department of Biological Sciences, University of Alberta, Edmonton, AB, T6G 2E9, Canada \#\#\#

\begin{abstract}
Photoprotective pigments, like those involved in the xanthophyll cycle, help plants avoid oxidative damage caused by excess radiation. This study aims to characterize a spectrum of strategies used to cope with light stress by a diverse group of prairie plants at Cedar Creek Ecosystem Science Reserve (East Bethel, MN). We find that concentrations of photosynthetic and photoprotective pigments are highly correlated with one another and with other physiological traits across species and over time, and tend to be phylogenetically conserved. During a period of water limitation, plots dominated by species with constitutively low pigment concentrations showed a greater decline in mean reflectance and photochemical reflectance index, a reflectance-based indicator of photoprotective physiology, possibly due to alterations in canopy structure. Our findings suggest two contrasting strategies for withstanding light stress: (1) Using photoprotective pigments to dissipate excess energy, and (2) altering canopy structure to minimize absorbance of excess radiation.
\end{abstract}

Additional key words: drought; light-use efficiency; phenology; photoinhibition; trait covariance; water-use efficiency.

\section{Introduction}

Plants use a number of photoprotective mechanisms to avoid photoinhibition and molecular damage caused by excessive radiation, which can lower their photosynthetic capacity (Demmig-Adams and Adams III 1996, Ashraf and Harris 2013). These mechanisms can be classified as tolerance mechanisms, which dissipate energy or quickly

Received 1 July 2017, accepted 6 November 2017, published as online-first 10 January 2018.

${ }^{+}$Corresponding authors; phone: (734) 502-2817, (612) 624-6337; e-mail: kotha020@umn.edu, e-mail: cavender@umn.edu

Abbreviations: Chl - total chlorophyll $(a+b)$ concentration; CWM - community-weighted mean; DPS - xanthophyll de-epoxidation state; ETR - electron transport rate; fAPAR - fraction of absorbed photosynthetically active radiation; $\mathrm{F}_{\mathrm{v}} / \mathrm{F}_{\mathrm{m}}$ - maximal quantum yield of PSII photochemistry; LUE - light-use efficiency; ML - maximum likelihood; NDVI - normalized difference vegetation index; NIR - near-infrared light; NPQ - nonphotochemical quenching; PC - principal component; PCA - principal component analysis; PRI - photochemical reflectance index; V+A+Z - xanthophyll pool size; VIS - visible light; WUE - intrinsic water-use efficiency; $\rho_{\mathrm{n}}$ - reflectance at wavelength $n$; $\Phi_{\text {PSII }}$ - effective quantum yield of PSII photochemistry.

Acknowledgements: We would like to thank staff at Cedar Creek Ecosystem Science Reserve, including Kally Worm and Troy Mielke. Funding to support this study was provided by a grant from the National Science Foundation (NSF) and National Aeronautics and Space Administraton (NASA) through the Dimensions of Biodiversity program (DEB-1342872) to J. Cavender-Bares, R. Montgomery, and J. Gamon. Additional support was provided by an NSF Long-Term Ecological Research grant to Cedar Creek (DEB-1234162) and an NSF Graduate Research Fellowship to S. Kothari under Grant No. 00039202. Jon Anderson determined percent cover of species in the field, Austin Pieper assisted with HPLC and pigment extraction, and Anna K. Schweiger and Cathleen Nguyen aided in interpreting the pigment concentrations from HPLC. All members of the Cavender-Bares Lab and Cristy Portales provided useful feedback on the research and manuscript.

(C) The Author(s). This article is published with open access at link.springer.com 
repair oxidative damage, or avoidance mechanisms, which alter whole-leaf light capture to reduce excess energy absorption (Steyn et al. 2002). One tolerance mechanism of photoprotection is the xanthophyll cycle, in which the two-step de-epoxidation of violaxanthin into zeaxanthin via the intermediate antheraxanthin allows plants to dissipate excess radiation through nonphotochemical quenching (NPQ) (Demmig-Adams and Adams III 1996, Müller et al. 2001).

Conditions that limit the amount of energy that can be captured by photosynthesis may force plants to dissipate more energy through these nonphotochemical means. For example, drought may limit photosynthesis by forcing plants to close their stomata, causing plants to upregulate pathways involved in NPQ, including the xanthophyll cycle. Consequently, xanthophyll cycle activity and xanthophyll pool sizes may be upregulated under conditions that limit light-use efficiency (LUE), including drought. Many other carotenoids, such as $\beta$-carotene and lutein, can also help by de-activating reactive oxygen species (Jahns and Holzwarth 2012), while other pigments, such as anthocyanins, may have other photoprotective roles, such as screening out light (Steyn et al. 2002). On the other hand, some species have avoidance mechanisms to reduce light interception, increase reflectance, or move chloroplasts away from the cell surface (Wada 2013). Avoidance mechanisms that involve modification of canopy structure have been described as "structural photoprotection" (Valladares and Pugnaire 1999). In short, species may use a variety of strategies to minimize light stress.

Lineages and functional groups of species often have consistent differences in function that reflect their varying ecological strategies (Donoghue 2008). However, the comparative ecology of photoprotection in terrestrial plants is little-studied (for examples, see Montgomery et al. 2008, Savage et al. 2009, Ramírez-Valiente et al. 2015), leaving it unclear to what extent photoprotective mechanisms show these patterns of structured variation among species. Furthermore, because photoprotection is tightly bound to other aspects of plant function, including photosynthesis and water relations, it is important to understand how variation across time and across species in the use of photoprotective pigments is related to other aspects of plant function. Do photoprotective traits correlate with other aspects of physiology to form a spectrum of strategies for response to light stress? Or do they constitute an independent axis of variation?

The comparative biology of photoprotection matters because measures of photoprotective activity are important in characterizing LUE to model primary productivity over large scales (Peñuelas et al. 2011, Garbulsky et al. 2011). Simple models of unstressed plants assume that LUE is constant, such that net primary productivity is proportional to absorbed photosynthetically active radiation (PAR) (Haxeltine and Prentice 1996). This assumption is often unrealistic - under natural conditions, plants do face stress, frequently causing declines in LUE whose severity may vary among sites based on their environmental conditions and whether they are dominated by species susceptible to light stress (Cavender-Bares and Bazzaz 2004). Habitats and regions vary in the functional composition and evolutionary history of their constituent species, and understanding the comparative physiology - including photoprotective physiology - of these species can help explain ecosystem-level properties. Previous studies have revealed large variation in photoprotective strategies among tree species in a single stand (Gamon et al. 2005), and between functionally distinct species that often inhabit different niches, such as deciduous and evergreen plants (Gamon et al. 1997, Springer et al. 2017). Given these findings, characterizing the extent of variation in photoprotective strategies among species from a single site could help in understanding how a range of strategies can succeed in a uniform environment.

To assess photoprotective and photosynthetic physiology over large spatial scales or with high temporal resolution, researchers often use nondestructive methods based on light reflectance spectra, which can often be assessed through remote sensing. One simple spectral index designed to track diurnal variation in xanthophyll cycle activity, and thus LUE, is the photochemical reflectance index (PRI), calculated as the normalized difference

$$
\text { PRI }=\frac{\rho_{531}-\rho_{570}}{\rho_{531}+\rho_{570}}
$$

where $\rho_{\mathrm{n}}$ denotes the percent reflectance at a wavelength of $n$ nanometers (Gamon et al. 1997). Since the development of the PRI, much research has shown that PRI is influenced not only by xanthophyll cycle activity ("facultative" changes, sensu Gamon and Berry 2012), but also the total pool size of xanthophylls and other pigments ("constitutive" changes, Gamon and Berry 2012), which corresponds to total photoprotective capacity. While constitutive changes occur more slowly, their influence is especially dominant in comparisons across species or over seasonal time scales (Stylinski et al. 2002, Sims and Gamon 2002, Wong and Gamon 2015). In both cases, changes associated with high photoprotection, and often low LUE large carotenoid pools and high xanthophyll de-epoxidation state-cause PRI to become lower, although PRI can also be influenced by other pigments, such as anthocyanins (Gitelson et al. 2017a).

At scales larger than the individual leaf, spectral characteristics of vegetation can also be influenced by the architecture of the canopy. At low levels of canopy closure or projected leaf area index - defned as one-sided leaf area per unit ground area - the signature of the soil background has a strong effect on remotely sensed spectra. Low plant cover and canopy architectures that make soil more visible from above can make remotely sensed PRI more dependent on the soil background (Barton and North 2001), weakening or erasing its relationship with leaf-level pigment concentrations and LUE (Soudani et al. 2014, Gitelson and Gamon 2015, Gitelson et al. 2017b). Abiotic drivers like drought can influence the structure of the 
canopy by causing mortality, altering phenology, and causing plants to modify their leaf display - for example, by leaf rolling (Kadioglu and Terzi 2007) or assuming more vertical leaf inclinations (Comstock and Mahall 1985, Gamon and Pearcy 1989, Joel et al. 1997), which under stressful conditions can help protect the photosynthetic function of the plant (Turgut and Kadioglu 1998, Pearcy et al. 2005, Nar et al. 2009). Consequently, both changes in leaf-level chemistry and canopy structure can cause remotely measured PRI to vary over time. This fact challenges the interpretation of remotely sensed PRI as a measure of leaf-level LUE or photosynthetic activity without controlling for canopy effects.

In this paper, we ask the following related questions:

How do the concentrations of xanthophyll-cycle

\section{Materials and methods}

Study site and species: We collected data from May to October 2014 at Cedar Creek Ecosystem Science Reserve in East Bethel, Minnesota. All measurements were collected in the Big Biodiversity Experiment (BioDIV or BigBio; E120), a biodiversity manipulation experiment comprising $9 \times 9 \mathrm{~m}$ plots seeded with $1,2,4,8$, or 16 tallgrass prairie species. (For this study, we ignore plotlevel diversity to consider the 16 species in isolation.) The 16 species included belong to five families, and include four functional groups: legumes, forbs, and $\mathrm{C}_{3}$ and $\mathrm{C}_{4}$ grasses (see the text table below). Within the species pool selected for this study, functional groups are monophyletic within the phylogeny, meaning that for this study, pigments and other pigments involved in photoprotection vary seasonally and across species within a diverse set of prairie plants?

Is species-level variation in photoprotective pigment concentrations related to broader aspects of plant physiology?

What community-wide consequences arise from species-level variation in photoprotection and associated physiological traits?

How are spectral indicators of photoprotective physiology influenced by leaf-level physiology and canopy structure at seasonal scales?

How might these patterns affect our ability to detect changing LUE associated with xanthophyll cycle activity using remote sensing?

functional groups and evolutionary history are closely linked. Within the 168 plots in BioDIV, we chose a subset of 35 plots in which to measure leaf-level physiological parameters, including 11 monoculture plots and 24 multispecies (between 2 and 16 species) plots. Each species was sampled in three distinct plots of varying diversity. Monocultures were not available for all 16 species in the study. Despite regular weeding, plots often contained species not originally planted in them (Kennedy et al. 2002); in all plots, we only measured species planted by design. Further details about the design of the experiment can be found in Tilman et al. (2001).

\begin{tabular}{llll}
\hline Species & Abbreviation & Family & Functional group \\
\hline $\begin{array}{l}\text { Koeleria macranta } \\
\text { (K. cristata) }\end{array}$ & koecr & Poaceae & $\mathrm{C}_{3}$ grass \\
Poa pratensis & poapr & Poaceae & $\mathrm{C}_{3}$ grass \\
Andropogon gerardii & andge & Poaceae & $\mathrm{C}_{4}$ grass \\
Panicum virgatum & panvi & Poaceae & $\mathrm{C}_{4}$ grass \\
Schizachyrium scoparium & schsc & Poaceae & $\mathrm{C}_{4}$ grass \\
Achillea millefolium & achmi & Asteraceae & Forb \\
Asclepias tuberosa & asctu & Apocynaceae & Forb \\
Liatris aspera & liaas & Asteraceae & Forb \\
Monarda fistulosa & monfi & Lamiaceae & Forb \\
Solidago rigida & solri & Asteraceae & Forb \\
Amorpha canescens & amoca & Fabaceae & Legume \\
Lespedeza capitata & lesca & Fabaceae & Legume \\
Lupinus perennis & luppe & Fabaceae & Legume \\
Petalostemum candidum & petca & Fabaceae & Legume \\
(Dalea candida) & & & \\
Petalostemum purpureum & petpu & Fabaceae & Legume \\
(Dalea purpurea) & & & \\
Petalostemum villosum & petvi & Fabaceae & Legume \\
(Dalea villosa) & & & \\
\hline
\end{tabular}

Pigment concentrations: At several points across the season, we assessed concentrations of carotenoids and chlorophyll (Chl) $a$ and $b$ in leaf tissue of individuals belonging to each species using high-performance liquid chromatography ( $n=327$ total) following previously described methods (Ramírez-Valiente et al. 2015). Briefly, 
we used a hole punch to collect disks from the youngest fully expanded leaf of each sampled individual. These disks were immediately wrapped in aluminum foil and stored in a liquid nitrogen Dewar until they could be stored in $\mathrm{a}-80^{\circ} \mathrm{C}$ freezer, where they were kept until analyzed with high-performance liquid chromatography (HPLC) on an Agilent 1200 HPLC system (Agilent Technologies Inc., Santa Clara, California, USA) at the University of Minnesota. For $\mathrm{Chl}$ and each carotenoid pigment, we used multiple calibration standards of known concentration to develop calibration equations in order to convert integrated areas of chromatogram peaks to concentrations.

We extracted anthocyanins $(n=761)$ from leaf disks by shaking them for $24 \mathrm{~h}$ with $-20^{\circ} \mathrm{C}$ acidified methanol $(0.1 \% \mathrm{HCl}, \mathrm{v} / \mathrm{v})$. We used a SpectraMax Plus 384 Plate Reader (Molecular Devices, Sunnyvale, CA, USA) to measure absorbance at $653 \mathrm{~nm}$ and $532 \mathrm{~nm}$, the peak absorbances of $\mathrm{Chl}$ and anthocyanins, respectively. About $25 \%$ of absorbance at $532 \mathrm{~nm}$ is due to $\mathrm{Chl}$, so we used the equation $\mathrm{AA}=\mathrm{A}_{653}-0.25 \times \mathrm{A}_{532}$ to estimate anthocyanin absorbance (AA) from raw absorbances (Murray and Hackett 1991). We estimated the final concentrations using a molar extinction coefficient of $28,000 \mathrm{~L}$ mol(anthocyanin $)^{-1} \mathrm{~cm}^{-1}$ (Lee et al. 2005).

We used the inferred pigment concentrations, in terms of nanograms per milligram of leaf tissue, to calculate metrics of xanthophyll-cycle activity, following Savage et al. (2009), including the total xanthophyll cycle pool size $(\mathrm{V}+\mathrm{A}+\mathrm{Z}$, where $\mathrm{V}$ is the concentration of violaxanthin, $\mathrm{A}$ is the concentration of antheraxanthin, and $Z$ is the concentration of zeaxanthin). We also calculated the deepoxidation state (DPS):

$$
\text { DPS }=\frac{0.5 \mathrm{~A}+\mathrm{Z}}{\mathrm{V}+\mathrm{A}+\mathrm{Z}}
$$

We summarized the species-level variation in pigment concentrations by performing a principal components analysis on the correlation matrix of species mean concentrations of total $\mathrm{Chl}, \mathrm{V}+\mathrm{A}+\mathrm{Z}$, neoxanthin, lutein, $\beta$-carotene, and anthocyanins.

Gas-exchange measurements $(n=166$ total) were taken from the uppermost fully expanded leaves of selected individuals of each species using a portable photosynthesis system (LI-6400 XT, LI-COR, Lincoln, NE, USA). We maintained a block temperature of $25^{\circ} \mathrm{C}$ and relative humidity of $40-60 \%$. Measurements were taken at ambient $\mathrm{CO}_{2}$ and a PPFD of $1,500 \mu \mathrm{mol}$ (photon) $\mathrm{m}^{-2} \mathrm{~s}^{-1}$ (red $+10 \%$ blue). We adjusted for leaves that did not cover the $6 \mathrm{~cm}^{2}$ leaf chamber by using a marker to indicate the part of the leaf that was enclosed, scanning the leaf, and using ImageJ software to measure the area (Schneider et al. 2012). We corrected for variation in enclosed area in all analyses.

We used gas-exchange measurements to calculate intrinsic water-use efficiency $\left(\mathrm{WUE}_{\mathrm{i}}\right)$ as the ratio of net photosynthetic rate $\left[\mu \mathrm{mol}\left(\mathrm{CO}_{2}\right) \mathrm{m}^{-2} \mathrm{~s}^{-1}\right]$ to stomatal conductance $\left[\mathrm{mol}\left(\mathrm{H}_{2} \mathrm{O}\right) \mathrm{m}^{-2} \mathrm{~s}^{-1}\right]$.
Chl fluorescence: We used a Hansatech FMS2 pulsemodulated $\mathrm{Chl}$ fluorometer to measure $\mathrm{Chl}$ fluorescence parameters throughout the season ( $n=590$ individuals). For each individual sampled at each sampling date, we took a dark-acclimated and a light-acclimated measurement on the newest fully expanded leaf. To collect darkacclimated measurements, we attached a leaf clip to each sampled leaf to block out sunlight for at least $30 \mathrm{~min}$. After taking each dark-acclimated measurement, we removed the clip and allowed the leaf to acclimate to ambient midday sunlight for at least $120 \mathrm{~min}$ before taking a lightacclimated measurement.

As a measure of the general stress level of plant leaves, we calculated the maximal dark-acclimated quantum yield $\left(\mathrm{F}_{\mathrm{v}} / \mathrm{F}_{\mathrm{m}}\right)$ as $\left(\mathrm{F}_{\mathrm{m}}-\mathrm{F}_{0}\right) / \mathrm{F}_{\mathrm{m}}$. We also calculated the electron transport rate as

$$
\mathrm{ETR}=0.5 \times 0.84 \times \Delta \mathrm{F} / \mathrm{F}_{\mathrm{m}}^{\prime} \times \mathrm{PPFD}
$$

where $\Delta F / F_{m}^{\prime}$, also notated $\Phi_{\text {PSII }}$, denotes the effective quantum yield of PSII, and PPFD is the photosynthetic photon flux density $\left[\mu \mathrm{mol}\left(\right.\right.$ photon) $\mathrm{m}^{-2} \mathrm{~s}^{-1}$. The constant 0.5 is based on the assumption that PSI and PSII apportion PAR equally; we treat leaf absorption as fixed when calculating ETR, so 0.84 represents a plausible absorption for the average leaf (Björkman and Demmig 1987).

Predawn water potential ( $n=70$ total) was measured with a Scholander pressure bomb in mid-June. Water potential data are reported in figures as the balancing pressure $[\mathrm{MPa}]$ used to counter the xylem tension, so reported values are positive, and more positive values represent more negative predawn water potential.

Spectral reflectance: Throughout the season, we used a UniSpec-SC portable leaf reflectometer (PP Systems, Amesbury, MA, US) to collect visible and near-infrared (VIS/NIR, 310-1,100 nm) hyperspectral reflectance spectra of multiple leaves from three individuals from each originally seeded species in each plot we sampled $(n=632$ individuals). Between plots, we used a white reference panel (Spectralon, Labsphere, North Sutton, NH, US) to collect a reference scan representing approximately $100 \%$ reflectance; measurements of leaves were calibrated against this scan. During data processing, we removed spectra that had peak reflectance below 0.3 or appeared clearly unlike a green leaf. At any given time point, the spectra for leaves of the same individual were averaged, and PRI was calculated from the average spectrum.

Every two weeks from late May through August, and once a month in September and October, we used a UniSpec-DC Spectral Analysis System to collect VIS/NIR (310-1,100 nm) hyperspectral reflectance spectra at the canopy scale in our plots, as well as in bare soil. The instrument collected upwelling radiance and downwelling irradiance simultaneously using two fiber optics. The upward-pointing fiber optic measured solar irradiance with a cosine head. The downward-pointing fiber optic had a 
field-of-view restrictor to limit the field-of-view to about $15^{\circ}$, resulting in a spatial resolution of about $0.5 \mathrm{~m}^{2}$. We collected a series of measurements for each plot by moving along the northern edge of the plot and taking a scan every $0.5 \mathrm{~m}$, taking care not to shadow the plot. We also collected a white reference scan before measuring each plot. We then calculated the reflectance at each measured wavelength $\lambda$ as

$$
\rho_{\lambda}=\frac{\mathrm{L}_{t, \lambda} / \mathrm{E}_{t, \lambda}}{\mathrm{L}_{p, \lambda} / \mathrm{E}_{p, \lambda}}
$$

where $\mathrm{L}$ and $\mathrm{E}$ refer to upwelling radiance and downwelling irradiance, respectively, and the subscripts $t$ and $p$ refer to measurements over the target plot and the calibration panel, respectively. The nominal bandwidth of the detectors (band-to-band spacing) was $3 \mathrm{~nm}$, so we used linear interpolation to reduce the spacing to $1 \mathrm{~nm}$. The spectra for a single plot at a given sampling date were averaged, and PRI was calculated from the plot-level average spectrum.

Plot-level reflectance spectra can be downloaded from the EcoSIS Spectral Library at doi:10.21232/C2Z070.

From the plot-level spectra, we also used the mean reflectance of bands from 350 to $1100 \mathrm{~nm}$ as a proxy for albedo, which is expected to increase with the amount of vegetation due to the high NIR reflectance of green leaf tissue. Mean reflectance, like other features of the reflectance spectrum, is influenced not only by the amount of vegetation but by the way it is projected horizontally; for example, more vertical leaf angles project less area when viewed from above, reducing the amount of visible vegetation.

Percent cover: We measured percent cover of each species in each of our 35 plots on 19 June and 1 August. Percent cover was evaluated in nine $0.5 \times 0.5 \mathrm{~m}$ subplots within each plot, positioned $1 \mathrm{~m}$ apart from each other $0.5 \mathrm{~m}$ from the plot's northern edge. We evaluated cover to the nearest percent below 20\%, and to the nearest $5 \%$ above that. For each subplot, bare ground was calculated so that total cover would add up to $100 \%$.

Climate and soil moisture: Daily precipitation and mean temperature records were collected at the Cedar Creek weather station, about $0.76 \mathrm{~km}$ away from the BioDIV experiment.

Once a month between May and September, we

\section{Results}

Determinants of plot-level PRI: Mean plot-level PRI increased during the early growing season, from late May to late June, then steadily declined during the hottest, driest part of the season, which occupied most of July (Figs. 1,2). Plot-level PRI reached a nadir in early August, after which it briefly peaked again following a handful of moderate measured soil moisture content at four depths using timedomain reflectometry in 38 representative plots sampled from the entire BioDIV experiment. We deployed a sensor (Trime FM, IMKO GmbH, Ettlingen, Germany) with a $17 \mathrm{~cm}$ long probe vertically into the soil inside a PVC tube at four depths: 3-20 cm, 20-37 cm, 80-97 cm, and 140$157 \mathrm{~cm}$. We calibrated the sensor using the same setup with wet and dry glass beads, in accordance with manufacturer's instructions.

Phylogenetic tree and comparative analyses: We created a phylogenetic tree of the species in the experiment using phyloGenerator (Pearse and Purvis 2013). The tree was built using rbcL sequences combined with a taxonomic constraint from Phylomatic (Webb and Donoghue 2005). First, a maximum likelihood (ML) estimate of the phylogeny was created using RAxML (Stamatakis 2006), followed by a BEAST run to estimate branch lengths under the ML topology (Drummond et al. 2006). Because phyloGenerator outputs an unrooted tree, we placed the root at the known split between Poaceae and the other species, which are all dicots. We then converted the tree into an ultrametric chronogram using the chronos function in the R package ape v. 4.1 (Paradis et al. 2004), using four estimated ages for ancestral nodes from Wikström et al. (2001), with additional estimates of node ages within families drawn from Kim et al. (2005) for Asteraceae, Lavin et al. (2005) for Fabaceae, and Giussani et al. (2016) for Poaceae. The time-calibrated, ultrametric phylogeny is available online as a supplement to this paper (Fig. 4S).

To assess phylogenetic conservatism in pigment and physiological traits, we calculated Blomberg's K (2003) for a selected set of traits. Using $R$ packages phytools 0.6 (Revell et al. 2012) and geiger 2.0.6 (Harmon et al. 2008), we compared the observed $\mathrm{K}$ value to the distribution of values expected under two null models: (1) A white noise model that maintains the structure of the phylogeny but swaps the tip labels, and (2) a simulation of Brownian motion trait evolution over the phylogeny. Rejecting null model (1) would suggest that evolutionary history influences values of a trait, such that more related species are more similar. Rejecting null model (2) suggests that trait values cannot be described as a random walk in which variance is proportional to evolutionary distance, a scenario of relatively high trait conservatism (mean $\mathrm{K}=1$ ).

All data analysis was performed in $R v$. 3.3.2 ( $R$ Core Team, 2016).

rains. Afterward, it underwent a late-season decline.

Plot-level PRI showed only a weak association with PRI at the leaf level (Fig. 2). Instead, PRI was linked to mean plot-level reflectance, which suggests that over seasonal time-scales in this system, PRI was driven largely by the amount of plant biomass, or its horizontal display. 


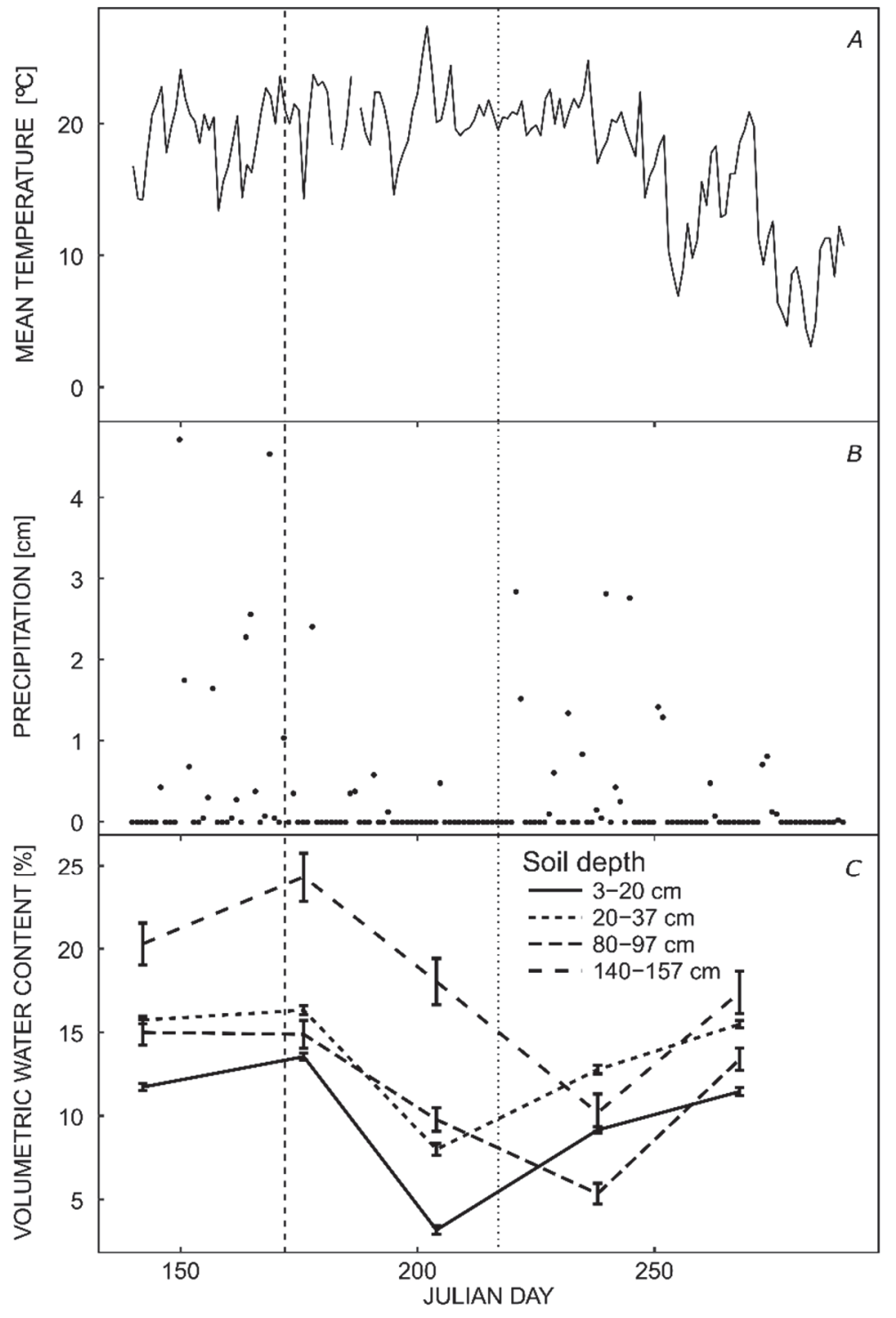

Fig. 1. (A) Mean daily temperature measured from the Cedar Creek weather station. (B) Daily precipitation measured from the Cedar Creek weather station. $(C)$ Volumetric water content $(\%)$ as measured by time-domain reflectometry at four soil depths in a set of BioDIV plots. Error bars denote \pm 1 SE. Dashed and dotted lines represent particularly wet and dry times in the growing season.
Across sampling dates, the mean plot-level PRI was strongly correlated with mean plot-level reflectance $\left(r^{2}=\right.$ 0.513; $p=0.018 ; n=9)$. Within a single sampling date, plot-level PRI showed significant correlations with plotlevel reflectance from May until early July ( $r^{2}$ from 0.1766 to $0.2732 ; p<<0.01 ; n=35)$, with no significant relationship afterward. Also corroborating the strong link between PRI and reflectance in the early season is the fact that variation in both quantities across plots was correlated with the amount of bare ground (Fig. 1S, supplement available online). Bare soil spectra collected had a mean PRI of -0.0975 , which was lower than $97.8 \%$ of our individual plot measurements. This indicates that an increased signal of the soil background would lower PRI in our system, consistent with the temporal dynamics.

Temporal dynamics of leaf-level physiology: Between the early growing season (May/June) and July, concentrations of all pigments declined steeply in most lineages
(Fig. 3). Because Chl concentrations declined more than $\mathrm{V}+\mathrm{A}+\mathrm{Z}$, the $(\mathrm{V}+\mathrm{A}+\mathrm{Z}) / \mathrm{Chl}$ ratio increased slightly during this period. At the same time, leaf-level PRI underwent a slight but noticeable decline, consistent with a role in tracking carotenoid/Chl ratios (Fig. 2C). [As expected, PRI was also negatively correlated with DPS across species (Fig. 4B).]

Despite an apparent lack of precipitation and a reduction in soil volumetric water content during July (Fig. 1), there was surprisingly little evidence for marked stress at the leaf level. Leaf-level PRI dipped slightly but remained fairly constant during this period (Fig. 2C), as did ETR and dark-acclimated $\mathrm{F}_{\mathrm{v}} / \mathrm{F}_{\mathrm{m}}$ (Fig. 2S, supplement available online). However, all of these traits eventually showed late-season declines likely associated with senescence (Fig. 2C, Fig. 2S).

Trait correlations and phylogenetic conservatism: Across species, mean concentrations of photosynthetic and 


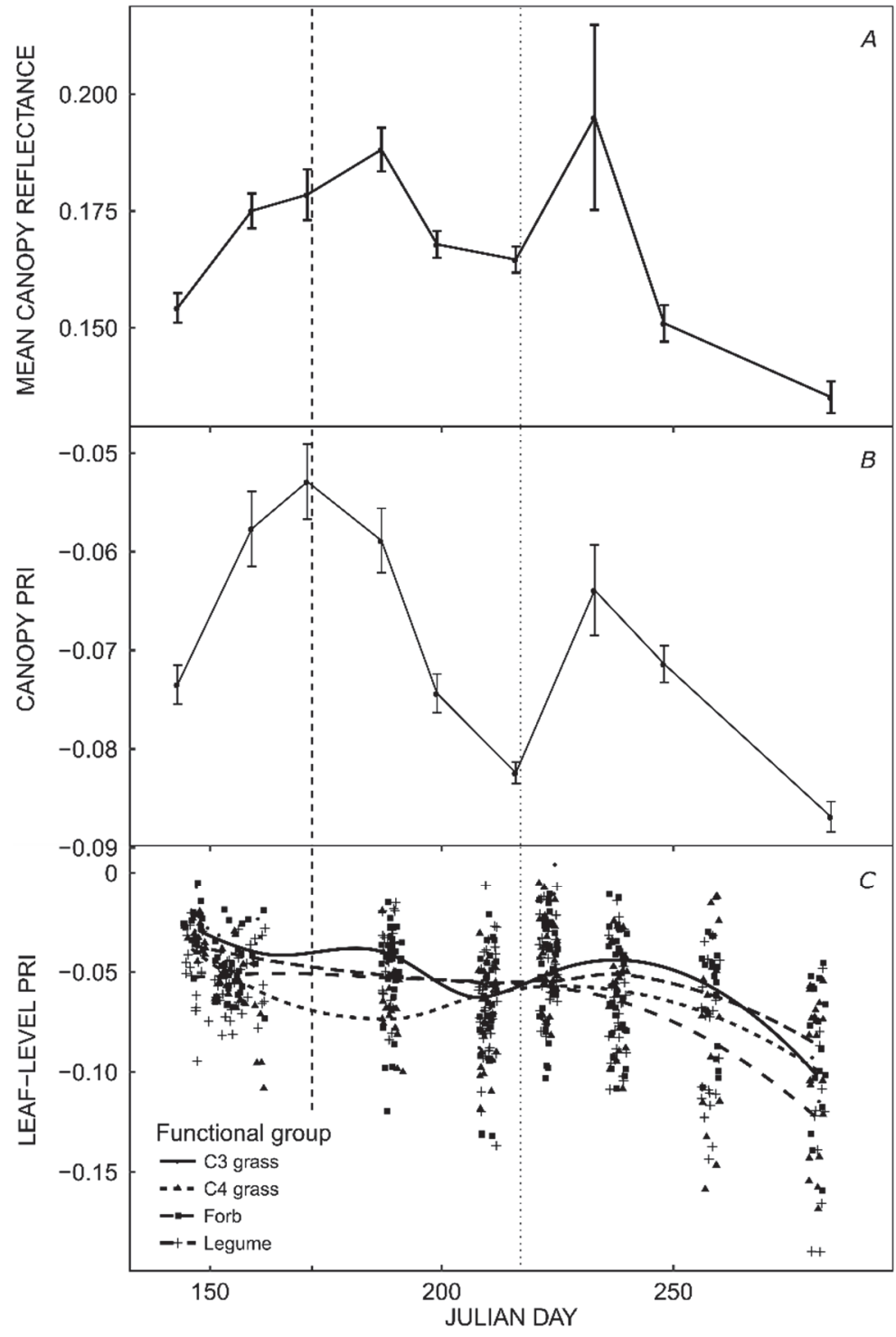

Fig. 2. (A) Mean plot-level reflectance from 350 to $1,100 \mathrm{~nm}$, calculated from full UniSpec-DC reflectance spectra over this spectral range. Error bars denote \pm 1 SE. (B) Plot-level measurements of PRI, calculated from UniSpec-DC spectra. Error bars denote \pm 1 SE. (C) Leaf-level PRI, separated by functional group. A small of jitter was added to points to avoid overplotting. Curves are LOESS fits with span $=0.75$. Vertical dashed and dotted lines represent particularly wet and dry times in the growing season. photoprotective pigments were strongly correlated with each other and with a suite of other physiological traits (Fig. 4B), including traits related to water use (WUE $\mathrm{W}_{\mathrm{i}}$, water potential) and photosynthesis (WUE, ETR, $\left.\mathrm{F}_{\mathrm{v}} / \mathrm{F}_{\mathrm{m}}\right)$. In a principal component analysis (PCA) of the correlation matrix between species means of a set of pigment traits, the first principal component (PC) explained $81.7 \%$ of the variation, and represented a general continuum from higher to lower constitutive pigment concentrations (Fig. 4A). Concentrations of photosynthetic pigments also appeared to be coordinated temporally; the early-season decline in pigment concentrations was shown in all pigments (Fig. 3).

Both pigment traits and other physiological traits tended to be conserved across the phylogeny (Fig. 5). Of the traits shown in Fig. 5, only predawn water potential did not show significant phylogenetic conservatism; for all other traits, a white noise null model was rejected, but a Brownian motion null model, which indicates clear conservatism, was not rejected.

Pigments and water limitation: We calculated a community weighted mean of the first PC of the PCA (Fig. $4 A$ ) by using June percent cover data to calculate the following weighted sum:

$$
\mathrm{CWM}_{p}=\sum_{i} \mathrm{c}_{i p} \mathrm{PC}_{i}
$$

where $\mathrm{c}_{i p}$ is the cover of species $i$ in plot $p$ and $\mathrm{PC}_{i}$ is the value of species $i$ along the first PC axis. As an index of response to water limitation, we subtracted the plot-level PRI and mean reflectance for each plot during a particularly wet period during late June (dashed line, Figs. 1,2) from the values during a drier period in early August (dotted line). The resulting differences are not a 


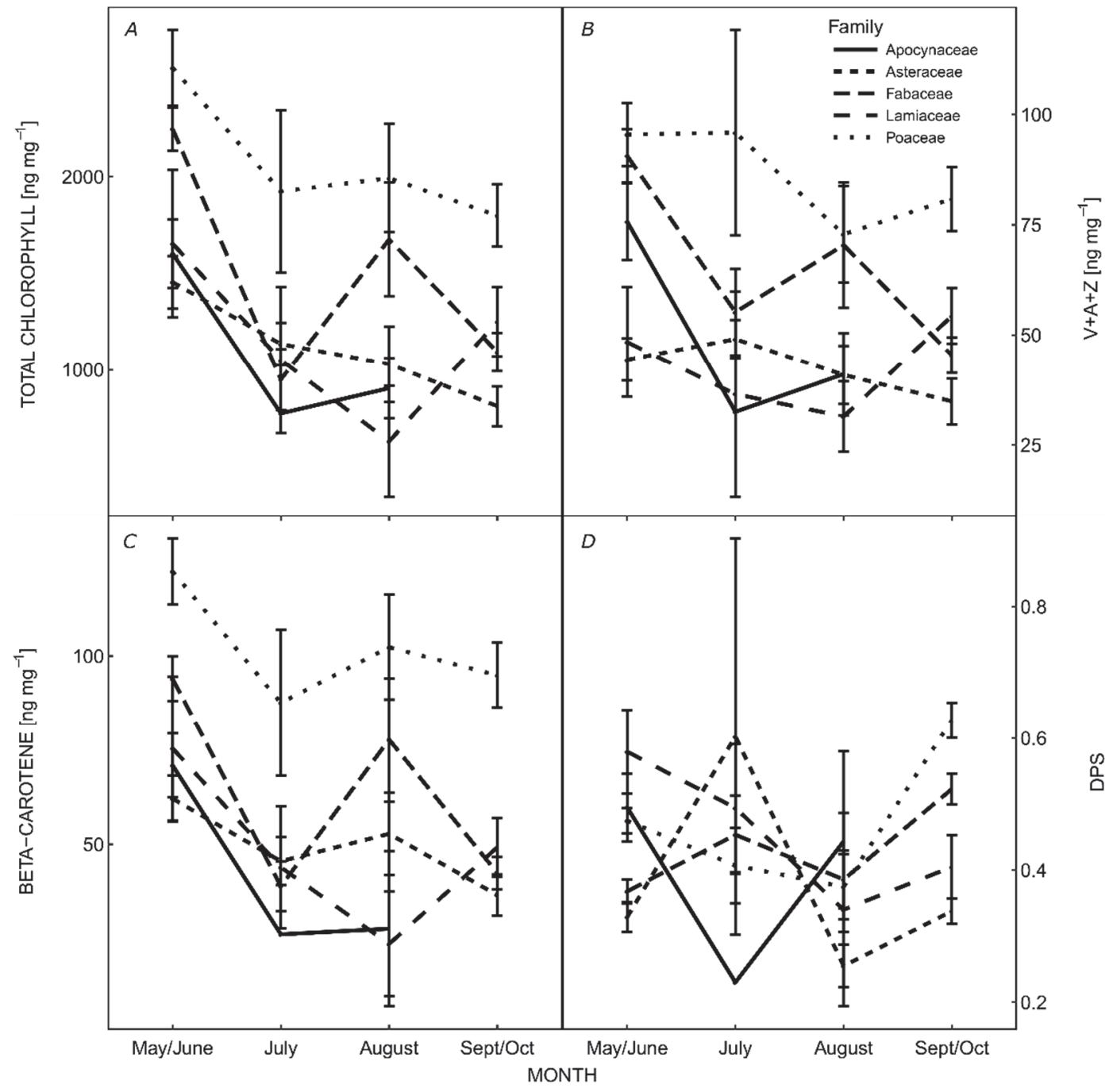

Fig. 3. Monthly variation in pigment traits, including $(A)$ total chlorophyll $\left[\mathrm{ng} \mathrm{mg}^{-1}\right.$ (fresh mass)] $(B) \mathrm{V}+\mathrm{A}+\mathrm{Z}\left[\mathrm{ng} \mathrm{mg}^{-1}\right.$ (fresh mass)], (C) $\beta$-carotene $\left[\mathrm{ng} \mathrm{mg}^{-1}\right.$ (fresh mass)], and $(D)$ DPS. Error bars denote $\pm 1 \mathrm{SE}$.

pure indicator of response to water limitation because species undergo typical phenological changes, and we are also not able to rule out responses to other environmental changes. However, of all species, only L. perennis declined significantly in percent cover between late June and early August. Furthermore, Wang et al. (2016) showed that only in eight- and sixteen-species plots (which included 12 of our 35 plots) did weighted mean plant height noticeably change after late June, and in these plots, height continued to increase into August. The fact that PǨI and mean reflectance declined sharply as the height

\section{Discussion}

Concentrations of photoprotective pigments show strong correlations, both across species and across time. This suggests that these pigment concentrations are coordinated as a suite of traits. Moreover, variation across species is structured phylogenetically and by functional group, with remained constant or increased makes it unlikely that the former is due purely to phenological change associated with the life cycle of plants. Instead, it seems most plausible that it is a stress response.

Regressions of change in plot-level PRI and mean reflectance against the community-weighted mean of the first PC axis showed that plots with low mean values on the first PC axis - plots whose dominant species have constitutively higher pigment concentrations - tended to show a smaller decrease (or even an increase) in mean reflectance and PRI (Fig. 6).

certain functional groups, like $\mathrm{C}_{4}$ grasses, having higher pigment concentrations than others, like forbs. This phylogenetic structure also corresponds with structure in other traits; $\mathrm{C}_{4}$ species, which have high pigment concentrations, also experience more negative predawn 

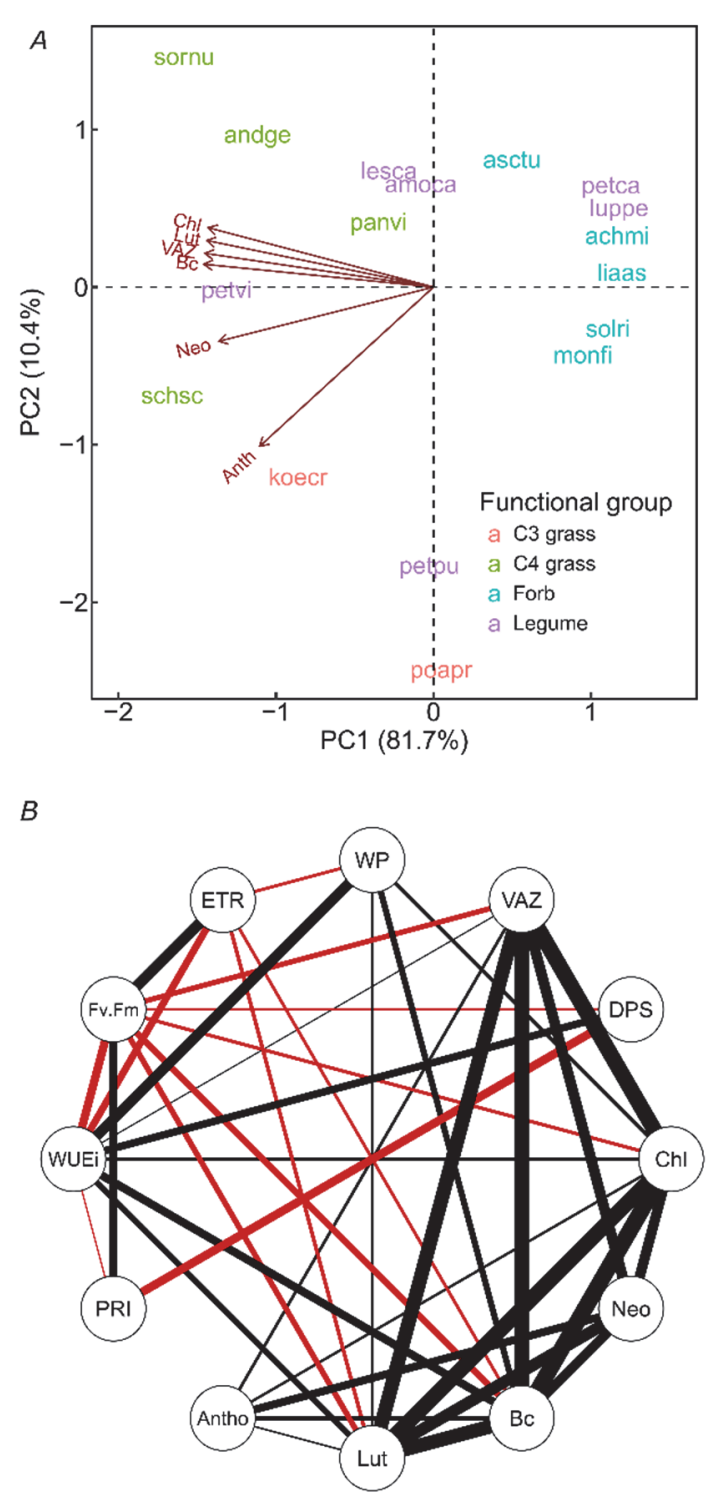

Fig. 4. (A) Principal component analysis (PCA) of species mean pigment concentrations. Colors represent taxonomic families. Scores and variable loadings are plotted along the first two principal components. PCA was performed on the correlation matrix, effectively giving all variables equal weight by scaling them to a mean of zero and variance of one. A small amount of jitter was added to reduce overlap among points and arrows. $(B)$ Correlations among species pigment and physiological traits. The width of an edge represents the absolute value of Pearson's correlation coefficient $r$ between two traits. Red edges denote negative correlations; black edges denote positive ones. Edges with $-0.5<r<0.5$ are not shown. Trait abbreviations in figures are as follows: $\mathrm{WP}$ - predawn water potential (expressed in terms of positive balancing pressure); VAZ - total xanthophyll pool size; DPS - xanthophyll de-epoxidation state; Chl - total chlorophyll concentration; Neo - neomycin concentration; $\mathrm{Bc}-$ $\beta$-carotene concentration; Lut - lutein concentration; Antho anthocyanin concentration; PRI - leaf-level photochemical reflectance index; $\mathrm{WUE}_{\mathrm{i}}$ - intrinsic water-use efficiency; $\mathrm{F}_{\mathrm{v}} / \mathrm{F}_{\mathrm{m}}-$ dark-acclimated maximum quantum yield; ETR - electron transport rate. water potential, and lower $F_{v} / F_{m}$ and ETR, but higher $\mathrm{WUE}_{\mathrm{i}}$, mostly driven by a higher net photosynthetic rate. Leaf-level PRI also showed modest but significant phylogenetic conservatism; this is consistent with findings that many parts of reflectance spectra are phylogenetically informative and conserved, which may contribute to the remote sensing of biodiversity (Cavender-Bares et al. 2016, McManus et al. 2016).

The trait correlations we found suggest a strategy for thriving in hot, dry environments, and in warmer, drier parts of the growing season, as $\mathrm{C}_{4}$ grasses often do (Edwards et al. 2010). Due to the $\mathrm{CO}_{2}$-concentrating mechanism of their bundle-sheath cells, $\mathrm{C}_{4}$ grasses can maintain their photosynthetic rates for some time even after limiting stomatal conductance (Ghannoum 2009), reducing their susceptibility to carbon starvation and hydraulic failure (Taylor et al. 2014). High concentrations of photoprotective pigments may also help in maintaining photosynthetic capacity in a stressful environment with high PAR and limited water. The ability to withstand stress and maintain growth during the dry mid-season may permit $\mathrm{C}_{4}$ grasses to coexist with other species through phenological niche partitioning (Fargione and Tilman 2005). In this context, the covariance and phylogenetic structure of pigment concentrations makes sense as part of a physiological strategy that allows later-maturing phenology.

Pigment concentrations were also coordinated with each other temporally (Fig. 3). Pigment concentrations declined in the early-to-midseason, which was surprising, given that xanthophyll pool size has been found to increase under mild drought in a meta-analysis (Wujeska et al. 2013). The declines may have been a result of ontogenetic changes in the developing leaves, as structural components like lignin and cellulose expand in their share of leaf mass (Miyazawa et al. 2003). Here, these ontogenetic changes may have overwhelmed the stress response. Nevertheless, $\mathrm{V}+\mathrm{A}+\mathrm{Z}$ declined less than other pigments, and even increased in some lineages, consistent with the trend in the meta-analysis.

Surprisingly, most aspects of leaf-level physiology remained nearly constant during the July mid-season, suggesting that most species were able to avoid adverse effects of water limitation and light stress on photosynthetic physiology at the leaf level (Fig. 2C, Fig. 2S). The extent of water limitation was likely mild, so traits that enabled tolerance or avoidance of mild stress may have enabled species to maintain physiological function and avoid severe damage. As expected, many traits showed clear signatures of senescence. PRI (Fig. 2C), darkacclimated $F_{\mathrm{v}} / \mathrm{F}_{\mathrm{m}}$, and ETR (Fig. 2S) all showed marked declines, indicating a breakdown in photosynthetic capacity and reduction in LUE. These traits, which all serve as indicators of photosynthetic downregulation, were strongly correlated at the level of individual means (Fig. 3S, supplement available online), and PRI and ETR were both correlated with $\mathrm{F}_{\mathrm{v}} / \mathrm{F}_{\mathrm{m}}$ (although not with each other) across species means (Fig. 4B), consistent with prior 

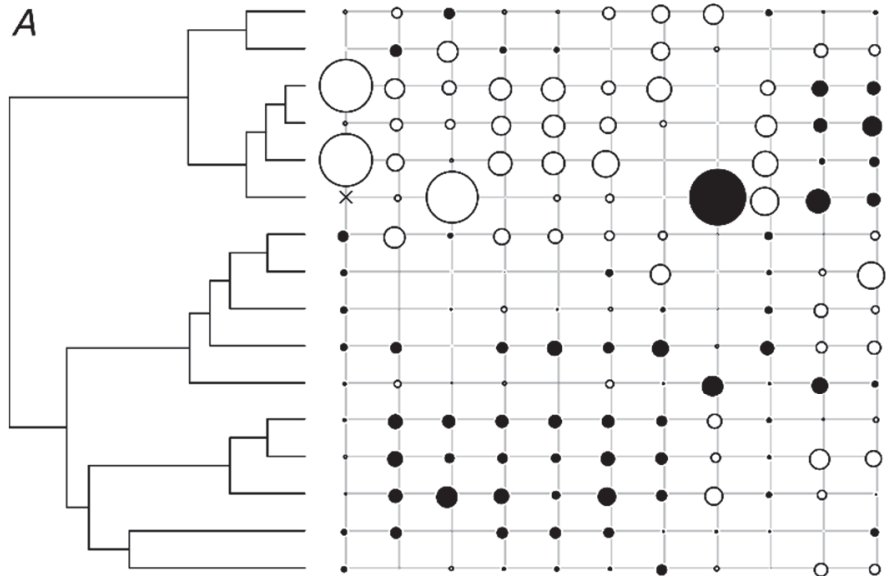

B koecr

poapr

schsc

andge

sornu

panvi

petvi

petpu

amocá

luppe

lesca

liaas

achmi

solri

monfi

asctu \begin{tabular}{ll|l|l|l|l|l|l|l|l|l|l|}
\hline Kobs & 0.40 & 0.62 & 0.57 & 0.73 & 0.94 & 0.83 & 0.80 & 0.51 & 1.30 & 0.64 & 0.64 \\
\hline
\end{tabular}

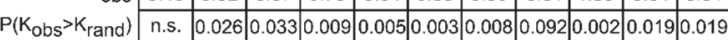

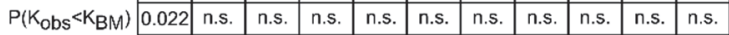

Fig. 5. (A) Phylogeny showing trait values of species in this study. All traits are shown normalized to a mean of zero and variance of one. Black circles denote negative values, while white circles denote positive values. The diameter of the circle represents the absolute value of the scaled trait. $X$ represents missing data for a trait-species combination. Species codes are in an in-text table. Trait abbreviations are as in Fig. 4. (B) Blomberg's $\mathrm{K}$ for each trait plotted on the tips of the phylogeny. Observed values were compared to null distributions generated by random tip-swaps and Brownian motion evolution along the phylogeny. Rows three and four, respectively, show the $p$-values of rejecting these null hypotheses. Only $p<0.1$ are shown.

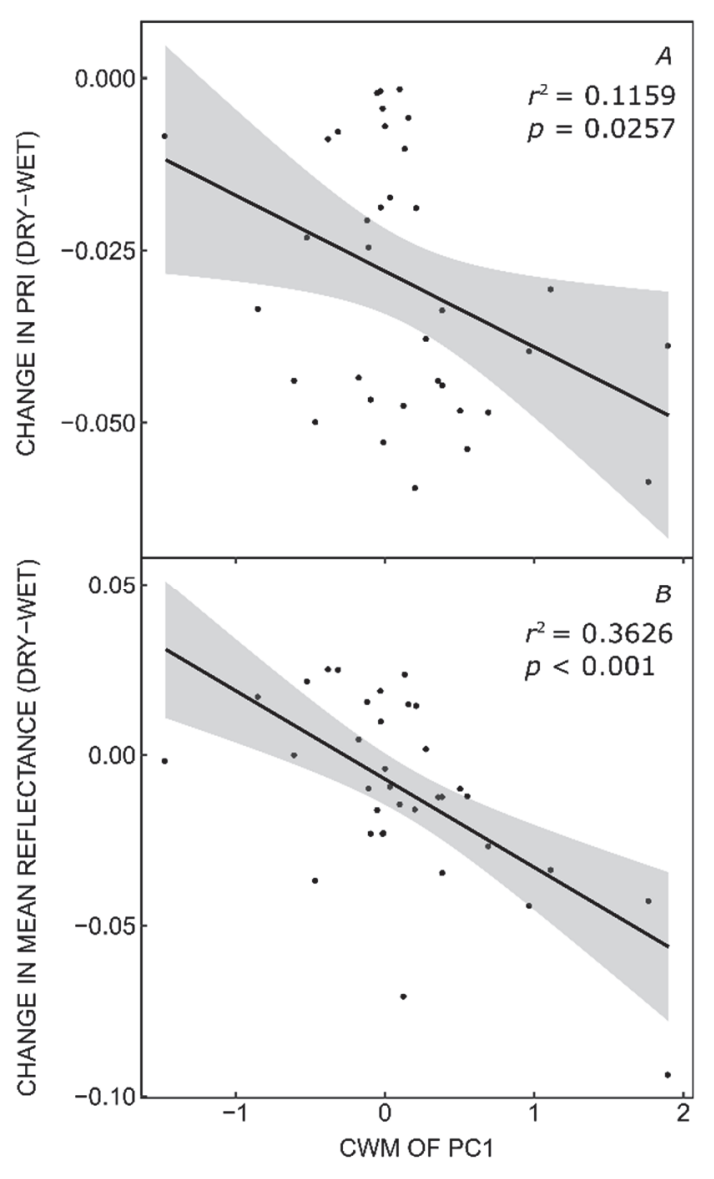

Fig. 6. Plot-level linear regression of the change in $(A)$ PRI and $(B)$ mean reflectance from wet to dry periods (blue and red in Fig. 1 and 2) against the community weighted mean of PC1 from Fig. $4 A$. Low values on the $\mathrm{x}$-axis represent higher constitutive pigment contents of the dominant species in a plot. Shaded areas represent $95 \%$ confidence intervals. research (Gamon et al. 1997, Peguero-Pina et al. 2008, Springer et al. 2017).

Given the relative stability of leaf-leaf physiology until the late season, it is evident that temporal variation in leaflevel PRI cannot fully explain the wide seasonal changes in plot-level PRI. Temporal patterns at both scales havesome similarities, including a late-season decline most likely caused by the onset of senescence. However, the trajectory of plot-level PRI has some features including a rise in the early growing season and a dip during the dry spell in early August - that are not shown, or not shown as clearly, in the leaf-level PRI. In these cases, changes in PRI are perhaps better explained by changes in total plot reflectance and soil visibility, a conclusion reinforced by the fact that inter-plot variation in PRI is strongly correlated with the amount of bare ground (Fig. 1S). The temporal changes may be driven by whole-plant growth during the early season, and by drought response for the mid-season decline, consistent with the findings of Gitelson et al. (2017b) in annual crops.

Studying the same plots during the same season, Wang et al. (2016) found that the normalized difference vegetation index (NDVI), a spectral index of greenness, also declined during this mid-season drought, which they explained as either a consequence of the drought or of anthesis, since many species (including $A$. gerardii, M. fistulosa, $P$. virgatum, $P$. purpureum, $P$. villosum, $S$. scoparium, and $S$. nutans) achieve peak flowering near that time. Flowers may decrease NDVI, depending on their reflectance spectrum (Joel et al. 1997, Shen et al. 2009), but their effect on PRI is unknown. It is unlikely that this decline is caused by elevated mortality, considering the low severity of the drought; in addition, Wang et al. (2016) found that the only species with significant declines in estimated cover between June and early August was L. perennis. Although we did not directly measure species 
structural responses to water limitation, it seems plausible that adaptive changes in canopy structure are responsible for some of this mid-season temporal variation.

Across plots and over the season, PRI appears to be strongly affected by canopy properties, both in terms of the amount of vegetative biomass and, potentially, the horizontal projection of these tissues. The late May-early June increase in plot-level PRI occurs despite an apparent decline in leaf-level PRI during the same time. This trend is likely due to rapid whole-plant growth in the early growing season, which increases the fraction of absorbed PAR (fAPAR) and overwhelms changes at the individual leaf level. The early August decline in plot-level PRI, which occurs without a similarly large decline in leaf-level PRI, may be due to drought responses such as leaf rolling or changes in leaf inclination. In this case, PRI may not indicate efficient use of intercepted light, but rather adaptive changes in canopy structure that allow plants to intercept less light, reducing fAPAR.

The possibility that remotely sensed PRI integrates both fAPAR and LUE that those species may use structural photoprotection as may help to explain its demonstrated success in tracking primary productivity over intervals longer than the diurnal time-scales for which it was designed (Garbulsky et al. 2011). However, it calls into question the mechanistic basis of remote sensing-based models of productivity that use PRI to measure LUE, because temporal and spatial variation in PRI may be due not just to variation in LUE, but also changes in canopy structure (Barton and North 2001, Gitelson et al. 2017b). Except over brief time periods, or in sites where canopy structure remains fairly constant, as in closed-canopy evergreen stands, canopy structure is likely to be the dominant control on PRI.

If adaptive changes in canopy structure do drive temporal variation in spectral characteristics, the fact that the plots that had the greatest mid-season decline in mean reflectance and PRI were ones dominated by species with low pigment concentrations (Fig. 6) suggests that those species may use structural photoprotection as an alternate strategy to reducing light stress. Rather than maintaining the suite of traits associated with tolerance of light stress and water limitation that $\mathrm{C}_{4}$ grasses have, these species may attempt to avoid light stress through changes in canopy structure to reduce light interception, which causes them to maintain lower leaf-level DPS and higher PRI. Some, but not all, of these species (especially the $\mathrm{C}_{3}$ grasses and L. perennis) may also grow and flower primarily in the cooler early season (Wang et al. 2016), another way of avoiding mid-season stress. The fact that plots dominated by $\mathrm{C}_{4}$ species saw lower mid-season declines in mean reflectance and PRI is likely due in large part to the $\mathrm{mid} /$ late-season dominated phenology of these species, rather than a direct effect of leaf-level physiology, but leaf-level traits - including photoprotective traits - are likely to facilitate the phenological strategies that these species have. Together, these traits of $\mathrm{C}_{4}$ species have consequences for whole-community properties, allowing plots, where they predominate, to stay productive even through water-limited parts of the growing season. On the other hand, plots with high abundances of some earlyseason dominants like $L$. perennis may face a rapid decline in productivity.

From the perspective of remote sensing of physiology, the existence of distinct strategies for photoprotection and drought response - avoidance $v s$. tolerance - supports the broader framework of "optical types," or distinct syndromes of linked traits that yield different signatures when sensed remotely (Ustin and Gamon 2010). Because these optical types correspond to functional roles, their existence can help explain the effectiveness of remote sensing in measuring biodiversity (Jetz et al. 2016) and scaling up plant physiology to whole ecosystems (Cavender-Bares and Bazzaz 2004, Ollinger et al. 2008). The potential for reflectance spectroscopy to provide an integrated picture of plant function means that it may be useful to treat diversity in spectral properties as a kind of biodiversity alongside functional, phylogenetic, and other betterrecognized dimensions of biodiversity (Cavender-Bares et al. 2017).

To commemorate Govindjee's $85^{\text {th }}$ birthday, we conclude with a brief note on his role in facilitating the ecophysiology of photosynthesis. The methods and paradigms that ecologists use to understand physiology and fitness in the context of whole communities are limited by the pace of advances in biochemistry and biophysics. Although most of Govindjee's research is not ecological, his seminal work on topics like chlorophyll $a$ fluorescence and the xanthophyll cycle illuminated how plants work in a truly integrative way. The challenge for ecologists is to translate this physiological understanding into the complex, multifactorial world of real, diverse plant communities.

Open Access This article is distributed under the terms of the Creative Commons Attribution License which permits any use, distribution, and reproduction in any medium, provided the original author(s) and the source are credited.

\section{References}

Ashraf M., Harris P.J.C.: Photosynthesis under stressful environments: An overview. - Photosynthetica 51: 163-190, 2013.

Barton C.V.M., North P.R.J.: Remote sensing of canopy light use efficiency using the photochemical reflectance index. -
Remote Sens. Environ. 78: 264-273, 2001.

Björkman O., Demmig B.: Photon yield of $\mathrm{O}_{2}$ evolution and chlorophyll fluorescence characteristics at $77 \mathrm{~K}$ among vascular plants of diverse origins. - Planta 170: 489-504, 1987. 
Blomberg S.P., Garland T., Ives A.R.: Testing for phylogenetic signal in comparative data: behavioral traits are more labile. Evolution 57: 717-745, 2003.

Cavender-Bares J., Bazzaz F.A.: From leaves to ecosystems: using chlorophyll fluorescence to assess photosynthesis and plant function in ecological studies. - In: Papageorgiou G.C., Govindjee (ed.): Chlorophyll $a$ Fluorescence: A Signature of Photosynthesis. Pp. 409-428. Springer, Dordrecht 2004.

Cavender-Bares J., Gamon J. A., Hobbie S. E. et al.: Harnessing plant spectra to integrate the biodiversity sciences across biological and spatial scales. - Am. J. Bot. 104: 966-969, 2017.

Cavender-Bares J., Meireles J.E., Couture J.J. et al.: Associations of leaf spectra with genetic and phylogenetic variation in oaks: prospects for remote detection of biodiversity. - Remote Sens. 8: 221,2016

Comstock J.P., Mahall B.E.: Drought and changes in leaf orientation for two California chaparral shrubs: Ceanothus megacarpus and Ceanothus crassifolius. - Oecologia 65: 531$535,1985$.

Demmig-Adams B., Adams W.W.III: The role of xanthophyll cycle carotenoids in the protection of photosynthesis. - Trends Plant Sci. 1: 21-26, 1996.

Donoghue M.J.: A phylogenetic perspective on the distribution of plant diversity. - P. Natl. Acad. Sci. USA 105: 11549-11555, 2008.

Drummond A.J., Ho S.Y.W., Phillips M.J. et al.: Relaxed phylogenetics and dating with confidence. - PLoS Biol. 4: e88, 2006.

Edwards E.J., Osborne C.P., Strömberg C.A.E. et al.: The origins of $\mathrm{C} 4$ grasslands: Integrating evolutionary and ecosystem science. - Science 328: 587-591, 2010.

Fargione J., Tilman D.: Niche differences in phenology and rooting depth promote coexistence with a dominant $\mathrm{C} 4$ bunchgrass. - Oecologia 143: 598-606, 2005.

Gamon J.A., Berry J.A.: Facultative and constitutive pigment effects on the Photochemical Reflectance Index (PRI) in sun and shade conifer needles. - Israel J. Plant. Sci. 60: 85-95, 2012.

Gamon J.A., Kitajima K., Mulkey S.S. et al.: Diverse optical and photosynthetic properties in a neotropical dry forest during the dry season: implications for remote estimation of photosynthesis. - Biotropica 37: 547-560, 2005.

Gamon J.A., Pearcy R.W.: Leaf movement, stress avoidance and photosynthesis in Vitis californica. - Oecologia 79: 475-481, 1989.

Gamon J.A., Serrano L., Surfus J.S.: The photochemical reflectance index: an optical indicator of photosynthetic radiation use efficiency across species, functional types, and nutrient levels. - Oecologia 112: 492-501, 1997.

Garbulsky M.F., Peñuelas J., Gamon J. et al.: The photochemical reflectance index (PRI) and the remote sensing of leaf, canopy and ecosystem radiation use efficiencies: A review and metaanalysis. - Remote Sens. Environ. 115: 281-297, 2011.

Ghannoum O.: C4 photosynthesis and water stress. - Ann. Bot.London 103: 635-644, 2009.

Gitelson A.A., Gamon J.A.: The need for a common basis for defining light-use efficiency: Implications for productivity estimation. - Remote Sens. Environ. 156: 196-201, 2015.

Gitelson A.A., Gamon J.A., Solovchenko A.: Multiple drivers of seasonal change in PRI: Implications for photosynthesis 1. Leaf level. - Remote Sens. Environ. 191: 110-116, 2017a.

Gitelson A.A., Gamon J.A., Solovchenko A.: Multiple drivers of seasonal change in PRI: Implications for photosynthesis 2.
Stand level. - Remote Sens. Environ. 190: 198-206, $2017 \mathrm{~b}$.

Giussani L.M., Gillespie L.J., Scataglini M.A. et al.: Breeding system diversification and evolution in American Poa supersect. Homalopoa (Poaceae: Poeae: Poinae). - Ann. Bot.London 118: 281-303, 2016.

Harmon L.J., Weir J.T., Brock C.D. et al.: GEIGER: investigating evolutionary radiations. - Bioinformatics 24: 129-131, 2008.

Haxeltine A., Prentice I.C.: A general model for the light-use efficiency of primary production. - Funct. Ecol. 10: 551-561, 1996.

Jahns P., Holzwarth A.R.: The role of the xanthophyll cycle and of lutein in photoprotection of photosystem II. - Biochim. Biophys. Acta 1817: 182-193, 2012.

Jetz W., Cavender-Bares J., Pavlick R. et al.: Monitoring plant functional diversity from space. - Nat. Plants 2: 16024, 2016.

Joel G., Gamon J.A., Field C.B.: Production efficiency in sunflower: The role of water and nitrogen stress. - Remote Sens. Environ. 62: 176-188, 1997.

Kadioglu A., Terzi R.: A dehydration avoidance mechanism: leaf rolling. - Bot. Rev. 73: 290-302, 2007.

Kennedy T.A., Naeem S., Howe K.M. et al.: Biodiversity as a barrier to ecological invasion. - Nature 417: 636-638, 2002.

Kim K.-J., Choi K.-S., Jansen R.K.: Two chloroplast DNA inversions originated simultaneously during the early evolution of the sunflower family (Asteraceae). - Mol. Biol. Evol. 22: 1783-1792, 2005.

Lavin M., Herendeen P.S., Wojciechowski M.F.: Evolutionary rates analysis of leguminosae implicates a rapid diversification of lineages during the tertiary. - Syst. Biol. 54: 575-594, 2005.

Lee J., Durst R.W., Wrolstad R.E.: Determination of total monomeric anthocyanin pigment content of fruit juices, beverages, natural colorants, and wines by the $\mathrm{pH}$ differential method: collaborative study. - J. AOAC Int. 88: 1269-1278, 2005.

McManus K.M., Asner G.P., Martin R.E. et al.: Phylogenetic structure of foliar spectral traits in tropical forest canopies. Remote Sens. 8: 196, 2016.

Miyazawa S.-I., Makino A., Terashima I.: Changes in mesophyll anatomy and sink-source relationships during leaf development in Quercus glauca, an evergreen tree showing delayed leaf greening. - Plant Cell Environ. 26: 745-755, 2003.

Montgomery R.A., Goldstein G., Givnish T.J.: Photoprotection of PSII in Hawaiian lobeliads from diverse light environments. - Funct. Plant Biol. 35: 595-605, 2008.

Müller P., Li X.-P., Niyogi K.K.: Non-photochemical quenching. A response to excess light energy. - Plant Physiol. 125: 15581566,2001

Murray J.R., Hackett W.P.: Dihydroflavonol reductase activity in relation to differential anthocyanin accumulation in juvenile and mature phase Hedera helix L. - Plant Physiol. 97: 343-351, 1991.

Nar H., Saglam A., Terzi R. et al.: Leaf rolling and photosystem II efficiency in Ctenanthe setosa exposed to drought stress. Photosynthetica 47: 429-436, 2009.

Ollinger S.V., Richardson A.D., Martin M.E. et al.: Canopy nitrogen, carbon assimilation, and albedo in temperate and boreal forests: Functional relations and potential climate feedbacks. - P. Nat. Acad. Sci. USA 105: 19336-19341, 2008.

Paradis E., Claude J., Strimmer K.: APE: Analyses of Phylogenetics and Evolution in R language. - Bioinformatics 20: 289-290, 2004.

Pearcy R.W., Muraoka H., Valladares F.: Crown architecture in sun and shade environments: assessing function and trade-offs 
with a three-dimensional simulation model. - New Phytol. 166: 791-800, 2005.

Pearse W.D., Purvis A.: phyloGenerator: an automated phylogeny generation tool for ecologists. - Methods Ecol. Evol. 4: 692-698, 2013.

Peguero-Pina J.J., Morales F., Flexas J. et al.: Photochemistry, remotely sensed physiological reflectance index and deepoxidation state of the xanthophyll cycle in Quercus coccifera under intense drought. - Oecologia 156: 1-11, 2008.

Peñuelas J., Garbulsky M.F., Filella I.: Photochemical reflectance index (PRI) and remote sensing of plant $\mathrm{CO}_{2}$ uptake. - New Phytol. 191: 596-599, 2011.

$\mathrm{R}$ Core Team.: R: A language and environment for statistical computing. R Foundation for Statistical Computing, Vienna, Austria, 2016. https://www.R-project.org/.

Ramírez-Valiente J.A., Koehler K., Cavender-Bares J.: Climatic origins predict variation in photoprotective leaf pigments in response to drought and low temperatures in live oaks (Quercus series Virentes). - Tree Physiol. 35: 521-534, 2015.

Revell L.J.: phytools: an R package for phylogenetic comparative biology (and other things). - Methods Ecol. Evol. 3: 217-223, 2012.

Savage J.A., Cavender-Bares J., Verhoeven A.: Willow species (genus: Salix) with contrasting habitat affinities differ in their photoprotective responses to water stress. - Funct. Plant Biol. 36: 300-309, 2009.

Schneider C.A., Rasband W.S., Eliceiri K.W.: NIH Image to ImageJ: 25 years of image analysis. - Nat. Methods 9: 671-675, 2012.

Shen M., Chen J., Zhu X. et al.: Yellow flowers can decrease NDVI and EVI values: evidence from a field experiment in an alpine meadow. - Can. J. Remote Sens. 35: 99-106, 2009.

Sims D.A., Gamon J.A.: Relationships between leaf pigment content and spectral reflectance across a wide range of species, leaf structures and developmental stages. - Remote Sens. Environ. 81: 337-354, 2002.

Soudani K., Hmimina G., Dufrêne E. et al:: Relationships between photochemical reflectance index and light-use efficiency in deciduous and evergreen broadleaf forests. Remote Sens. Environ. 144: 73-84, 2014.

Springer K., Wang R., Gamon J.: Parallel seasonal patterns of photosynthesis, fluorescence, and reflectance indices in boreal trees. - Remote Sens. 9: 691, 2017.
Stamatakis A.: RAxML-VI-HPC: maximum likelihood-based phylogenetic analyses with thousands of taxa and mixed models. - Bioinformatics 22: 2688-2690, 2006.

Steyn W.J., Wand S.J.E., Holcroft D.M. et al.: Anthocyanins in vegetative tissues: a proposed unified function in photoprotection. - New Phytol. 155: 349-361, 2002.

Stylinski C., Gamon J., Oechel W.: Seasonal patterns of reflectance indices, carotenoid pigments and photosynthesis of evergreen chaparral species. - Oecologia 131: 366-374, 2002.

Taylor S.H., Ripley B.S., Martin T. et al.: Physiological advantages of $\mathrm{C} 4$ grasses in the field: a comparative experiment demonstrating the importance of drought. - Glob. Change Biol. 20: 1992-2003, 2014.

Tilman D., Reich P.B., Knops J. et al.: Diversity and productivity in a long-term grassland experiment. - Science 294: 843-845, 2001.

Turgut R., Kadioglu A.: The effect of drought, temperature and irradiation on leaf rolling in Ctenanthe setosa. - Biol. Plantarum 41: 629-633, 1998.

Ustin S.L., Gamon J.A. Remote sensing of plant functional types. - New Phytol. 186: 795-816, 2010.

Valladares F., Pugnaire F.I.: Tradeoffs between irradiance capture and avoidance in semi-arid environments assessed with a crown architecture model. - Ann. Bot.-London 83: 459-469, 1999.

Wada M.: Chloroplast movement. - Plant Sci. 210: 177-182, 2013.

Wang R., Gamon J.A., Montgomery R.A. et al.: Seasonal variation in the NDVI-species richness relationship in a prairie grassland experiment (Cedar Creek). - Remote Sens. 8: 128, 2016.

Webb C.O., Donoghue M.J.: Phylomatic: tree assembly for applied phylogenetics. - Mol. Ecol. Notes 5: 181-183, 2005.

Wikström N., Savolainen V., Chase M.W.: Evolution of the angiosperms: calibrating the family tree. - P. Roy. Soc. Lond. B Bio. 268: 2211-2220, 2001.

Wong C.Y.S., Gamon J.A.: Three causes of variation in the photochemical reflectance index (PRI) in evergreen conifers. New Phytol. 206: 187-195, 2015.

Wujeska A., Bossinger G., Tausz M.: Responses of foliar antioxidative and photoprotective defence systems of trees to drought: a meta-analysis. - Tree Physiol. 33: 1018-1029, 2013. 